\title{
THE ASSESSMENT OF THE IMPACT OF A TRAINING PROCESS ON THE HABITUATION OF THE VESTIBULAR-VEGETATIVE SYSTEM, USING A SPECIAL ROTATIONAL TEST AS A CONDITION OF MAINTAINING FLIGHT SAFETY
}

\section{ZBIGNIEW WOCHYŃSKI ${ }^{1}$, PIOTR KRAWCZYK ${ }^{2}$, and KRZYSZTOF CUR ${ }^{3}$}

\author{
${ }^{1}$ Polish Air Force University, Dęblin, Poland \\ Department of Aviation Safety Transport \\ ${ }^{2}$ Polish Air Force University, Dęblin, Poland \\ Department of Aviation \\ ${ }^{3} 3$ rd Airlift Wing, Powidz, Poland
}

\begin{abstract}
Objectives: The authors formulated a hypothesis that, on completion of the training program by cadets, their vestibular habituation would increase, measured by the time of the duration of the test on the unlocked looping, in contrast to the initial values and the control group. Material and Methods: The research involved 35 male cadets, first-year students of the Polish Air Force Academy in Dęblin. The examined persons were on average 20 years of age. They were divided into 2 groups. Group A ( $N=25$, tested) continued training on Special Aviation Gymnastic Instruments (SAGI). The cadets were a homogeneous group of participants in the jet pilot course, selected by the Military Aeromedical Board. Group B ( $\mathrm{N}=10$, control) conducted the standard physical military education program. Groups A and B were tested on the unlocked looping before and after the training process. In the training process, the groups had heart rate (HR) monitored. Results: The cadets in group A on the test in the unlocked looping, at the beginning of the training period, had an average score of $468.5 \pm 96.6 \mathrm{~s}$, and on completion of the training period $575.6 \pm 47.9 \mathrm{~s}$, which is a statistically significant difference at $\mathrm{p}<0.000001$. Similarly, the examined individuals in group B received an average score of $396.2 \pm 31.8 \mathrm{~s}$, and at the end of the training period $473.4 \pm 72.0 \mathrm{~s}$, which is a statistically significant difference at $\mathrm{p}<0.01$. In group A, a statistically significant decrease in the average HR value was observed. In group B, there was a statistically significant increase in the average HR value. Conclusions: The exercises on SAGI have a beneficial impact on improving the habituation of the vestibular organ in training cadets in examination II, as opposed to examination I and the control group. Int J Occup Med Environ Health. 2020;33(4):497-506
\end{abstract}

Key words:

space motion sickness, special aviation gymnastic instruments, test on the unlocked looping, vestibular-vegetative system, training process, Coriolis effect

Funding: this study was supported by the National Centre for Research and Development in 2009-2010 as a developmental project (No. O R/00 001706 entitled "The training system that increases the efficiency of the balance system and sight - movement coordination of multi-task aircraft pilots," project manager: Marek Grzegorzewski, Ph.D.)

Received: July 10, 2019. Accepted: April 20, 2020.

Corresponding author: Zbigniew Wochyński, Polish Air Force University, Department of Aviation Safety Transport, Dywizjonu 303 12, 08-521 Dęblin, Poland (e-mail: zbigniew.wochynski@op.pl). 


\section{INTRODUCTION}

The process of training on Special Aviation Gymnastic Instruments (SAGI) is essential for shaping spatial orientation and resistance to space motion sickness in pilots. It is a basic element of ensuring flight safety. In contemporary military aviation, research into the sensitivity of the vestibular-vegetative system in pilots is a vital factor in the selection of candidates for pilots. Scientists continuously seek effective tools for the diagnosis of the habituation of the vestibularvegetative system on a permanent basis. In the preliminary selection of candidates for aviation, the Coriolis effect is used (Bárány rotational chair) with the appropriate methodology to determine the degree of sensitivity of the vestibular organ, and thus the resistance to angular accelerations.

Over the years, the Coriolis effect has been applied in experimental research [1-3] as well as in the ground preparation of astronauts. To a lesser extent, it is useful for diagnosing the habituation of the vestibular-vegetative system after the preparatory phase for flights. In the training process, the level of obtaining vestibular habituation was assessed by means of a rotational attempt on the unlocked looping (Jędrys test) [4]. Due to the specific environment of the pilot's job, the training process is conducted on SAGI. Exercises on SAGI include exercises on a looping, an aero-wheel and a gyroscope. Their impact on human body and photographs demonstrating specific instruments were shown in other scientific works [5-7].

Conducting special training for pilots is considered to be a challenge among training tasks. In the process of an optimal preparation of a pilot for flights, the most important factor in this environment is to achieve adequate vestibular habituation, which increases tolerance to angular accelerations [8-10]. It is a pre-requisite for flight safety. The vestibular organ is part of the bony labyrinth, composed of 3 semicircular canals, whose sensory cells respond to angular accelerations [10].

In aviation, spatial disorientation is mainly linked with the vestibular organ, resulting from a reduced perception of the semicircular canals. The symptoms associated with balance occurring during accelerations are quite significant. They include dizziness, nausea, vomiting, depression, etc. [11]. The above-mentioned symptoms can be eliminated by means of SAGI exercises, leading to vestibular habituation. It was proved that SAGI training has a beneficial impact on the habituation of the organ by expanding the time of tolerance for Coriolis accelerations and a reduction in the intensity of the occurrence of vegetative symptoms [12]. An earlier study confirmed improvement in the tolerance of the sense of balance on the unlocked looping at the end of the training process on SAGI [4]. Due to the rapid development of military aviation, scientific investigations are being conducted on a continuous basis, searching for new diagnostic and training solutions in the modern pilot's preparation for flying. Bearing in mind modern flight safety regulations, it is observed that apart from technical reasons and emergencies, accidents occur as a result of human error during work. The most common causes of accidents are the effects of an imbalance between situational requirements and human capabilities $[8,10,13]$. Therefore, the study attempts at assessing the vestibularvegetative system in pilots, before and after the process of special preparation on SAGI. The authors used a test on the unlocked looping, which differs from the Coriolis effect by the fact that it is a cardiac diagnostic test, which is more sensitive after the training process due to its duration and body reactions.

A hypothesis was formulated that, on completion of the training program on SAGI by cadets, holders of health category 1 , their vestibular habituation would increase, measured by the time of the duration of the test on the unlocked looping in contrast to the initial values and the control group.

\section{MATERIAL AND METHODS}

\section{Examining the population}

The research involved 35 male cadets, first-year students of the Polish Air Force Academy (PAFA) in Dęblin. 
The examined persons were on average 20 years of age. They were divided into 2 groups. Group A $(\mathrm{N}=25$, tested) underwent training on SAGI. The group was a homogeneous material made up of students on a jet pilot course, selected by the Military Aeromedical Board, who obtained the highest health category (Z-1A). Group B ( $\mathrm{N}=10$, control) implemented a standard program of physical education in military schools, achieving health category Z-1C.

\section{Method of research}

The test was conducted on the unlocked looping [4] at the beginning (examination I) and at the end (examination II) of the training process. The test result is established on the basis of its duration.

In order to assess the intensity and monitor cadet training, the authors used the Polar Team2 Pro system to register heart rate (HR) changes.

\section{Ethical issues}

The consent for the research was granted by the Ethics Committee of the Military Institute of Aviation Medicine in Warsaw - decision No. 03A/2009 of July 8, 2009.

\section{Standard program of physical education}

The program of physical education was conducted through a thorough development of the examinees. During the program, there was a focus on all motor skills. The classes were conducted as tasks and by repetition. The themes were related to gymnastics, outdoor athletics and team games.

\section{Training program on SAGI}

The cadets completed a detailed program on SAGI, following the latest trends in methodology [14]. The activities were conducted in the form of tasks and by repetition, including the methodological highlights of the training process included in the program.
In both groups, the training period consisted of twenty 2-h training units, which was completed within 70 days, cyclically twice a week. The cadets were provided with identical food and accommodation conditions during the whole training period. The cadets received a standard diet in accordance with the rules of mass catering. The daily food ration, on average, consisted of $4500 \mathrm{kcal}$, including $150 \mathrm{~g}$ fats $(30 \%), 112.5 \mathrm{~g}$ proteins $(10 \%)$ and $675 \mathrm{~g}$ carbohydrates $(60 \%)$.

\section{Description of an attempt on the unlocked looping}

The exercise was performed in a standing position on the unlocked looping. With the help of a partner, the examinee was rotated in the longitudinal axis, at a frequency of 1 revolution/2 s. During the revolution, the tested person moved their head in the following order: head up straight, head down, rotation to the left (the chin touches the left collar-bone), rotation to the right (the chin touches the right collar-bone), head up straight. The examinee was required to hold each position for $2 \mathrm{~s}$. The test was stopped once the symptoms of space motion sickness occurred [4]. The test is highly significant from the practical and diagnostic point of view. It is easy to perform before and after a workout. The evaluation criteria consist in the execution of the above-mentioned movements within specified time constraints: $600 \mathrm{~s}$ - very well; $480 \mathrm{~s}$ - well; $360 \mathrm{~s}$ - sufficiently. The attempt was interrupted immediately when the symptoms of space motion sickness (strong nausea and vomiting) appeared. The symptoms of space motion sickness include malaise, sudden paleness, sweating, strong nausea, vomiting - the examination was interrupted as soon as they occurred.

\section{Statistical analysis}

In the analysis of the results of the examination, descriptive statistics was used by calculating the mean and standard deviations for all the examined variables. The normal distribution of the variables was checked by means of 
the Kolmogorov-Smirnov test. The assessment of the equality of variances was conducted by means of Levene's test. The difference between the variables in the 2 groups before and after the preparation was calculated by applying the mean of the Bonferroni test. The difference between the variable groups was obtained through the analysis of variance (ANOVA). The statistical analysis of the research findings was conducted using statistical software Statistica 9.0. The differences between mean values were considered significant when the calculated value of $p$ was $<0.05$.

\section{RESULTS}

The obtained results showed statistically insignificant differences in such parameters as age, height, body weight and BMI after the period of training in relation to the output values (Table 1).

In group A, in examination II, the cadets obtained a $19 \%$ increase in the test time on the unlocked looping in relation to examination I, which is a statistically significant difference at $p<0.000001$ (Table 2). In group B, in examination II, the cadets obtained a $17 \%$ increase in the test time on the unlocked looping in relation to examination I, which is a statistically significant difference at $\mathrm{p}<0.01$ (Table 2). In examinations I and II, a statistically significant difference between groups A and B was found with regard to the values of the test duration with $\mathrm{p}<0.05$, and later $\mathrm{p}<0.00005$, to the advantage of group A (Table 2). The individual results achieved by cadets in groups $\mathrm{A}$ and $\mathrm{B}$ in the unlocked looping test, in examinations I and II, are depicted in Figure 1 and 2.

Group A showed a statistically significant decrease in HR (of $8 \%$ ) in examination II compared to examination I, at $\mathrm{p}<0.000001$ in cadet pilots (Table 2). Group B demonstrated a statistically significant HR increase of $8 \%$ in examination II in relation to examination I, at $\mathrm{p}<0.0002$. In examinations I and II, a statistically significant difference was found between groups A and B in HR mean values at $\mathrm{p}<0.000001$ (Table 2).
Table 1. Characteristics of the examined cadet pilots before and after the preparation period on the unlocked looping in group $\mathrm{A}(\mathrm{N}=25$, tested $)$ and group $\mathrm{B}(\mathrm{N}=10$, control $)$ of first-year students of the PAFA in Dęblin

\begin{tabular}{|c|c|c|}
\hline \multirow{3}{*}{ Variable } & \multirow{2}{*}{\multicolumn{2}{|c|}{$\begin{array}{l}\text { Participants } \\
(\mathrm{N}=35) \\
\text { examination }\end{array}$}} \\
\hline & & \\
\hline & I & II \\
\hline \multicolumn{3}{|l|}{ Age [years] $(\mathrm{M} \pm \mathrm{SD})$} \\
\hline group A & $20.7 \pm 1.35$ & $20.7 \pm 1.35$ \\
\hline group B & $19.2 \pm 0.42$ & $19.2 \pm 0.42$ \\
\hline \multicolumn{3}{|c|}{ Body height $[\mathrm{cm}](\mathrm{M} \pm \mathrm{SD})$} \\
\hline group A & $175.9 \pm 4.80$ & $175.9 \pm 4.80$ \\
\hline group B & $173.1 \pm 5.59$ & $173.1 \pm 5.59$ \\
\hline \multicolumn{3}{|c|}{ Body weight $[\mathrm{kg}](\mathrm{M} \pm \mathrm{SD})$} \\
\hline group A & $70.4 \pm 6.02$ & $69.6 \pm 6.50$ \\
\hline group B & $66.14 \pm 6.01$ & $66.15 \pm 3.73$ \\
\hline \multicolumn{3}{|c|}{$\mathrm{BMI}\left[\mathrm{kg} \times \mathrm{m}^{-2}\right](\mathrm{M} \pm \mathrm{SD})$} \\
\hline group A & $22.8 \pm 1.89$ & $22.5 \pm 2.03$ \\
\hline group B & $22.15 \pm 2.04$ & $22.14 \pm 1.28$ \\
\hline
\end{tabular}

p - statistically non-significant.

Examination I - before the preparation period;

II - after the preparation period.

In groups $\mathrm{A}$ and $\mathrm{B}$, in examinations I and II, the individual HR values were presented graphically in Figure 3.

\section{DISCUSSION}

The results of the conducted examination showed that in groups $\mathrm{A}$ and $\mathrm{B}$, the training process caused an increase in the habituation level of the vestibular-vegetative system. In both groups, it was possible to observe a statistically significant increase in the average duration of the test on the unlocked looping in examination II (after ending the training process on SAGI) in contrast to examination I. Group A was found to have mean duration time values significantly higher than in group B, in examinations I and II. It can be explained by the fact that group A underwent a different training program 
Table 2. Test results on the unlocked looping before and after the preparation period in group A ( $\mathrm{N}=25$, tested) and group $\mathrm{B}(\mathrm{N}=10$, control) of first-year students of the PAFA in Dęblin

\begin{tabular}{lccc}
\hline \multirow{2}{*}{ Variable } & \multicolumn{2}{c}{ Examination } & \multirow{2}{*}{$\mathrm{p}$} \\
\cline { 2 - 3 } & $\mathrm{I}$ & $\mathrm{II}$ & \\
\hline Attempt on the unlocked looping [s] $(\mathrm{M} \pm \mathrm{SD})$ & & & $<0.000001$ \\
$\quad$ group A & $468.5 \pm 96.6^{*}$ & $575.6 \pm 47.9^{* *}$ & $<0.01$ \\
group B & $396.2 \pm 31.8$ & $473.4 \pm 72.0$ & \\
Training unit HR [bpm] $(\mathrm{M} \pm \mathrm{SD})$ & & & $<0.000001$ \\
group A & $114.5 \pm 5.48^{* * *}$ & $105.4 \pm 4.02 * * *$ & $<0.0002$ \\
group B & $130.0 \pm 5.73$ & $139.8 \pm 2.48$ & \\
\hline
\end{tabular}

* Statistically significant difference between the groups in examination I with $\mathrm{p}<0.05$.

** Statistically significant difference between the groups in examination II at $\mathrm{p}<0.0005$.

*** Statistically significant difference between the groups in examination I at $\mathrm{p}<0.000001$.

Examination I - before the preparation period; II - after the preparation period.

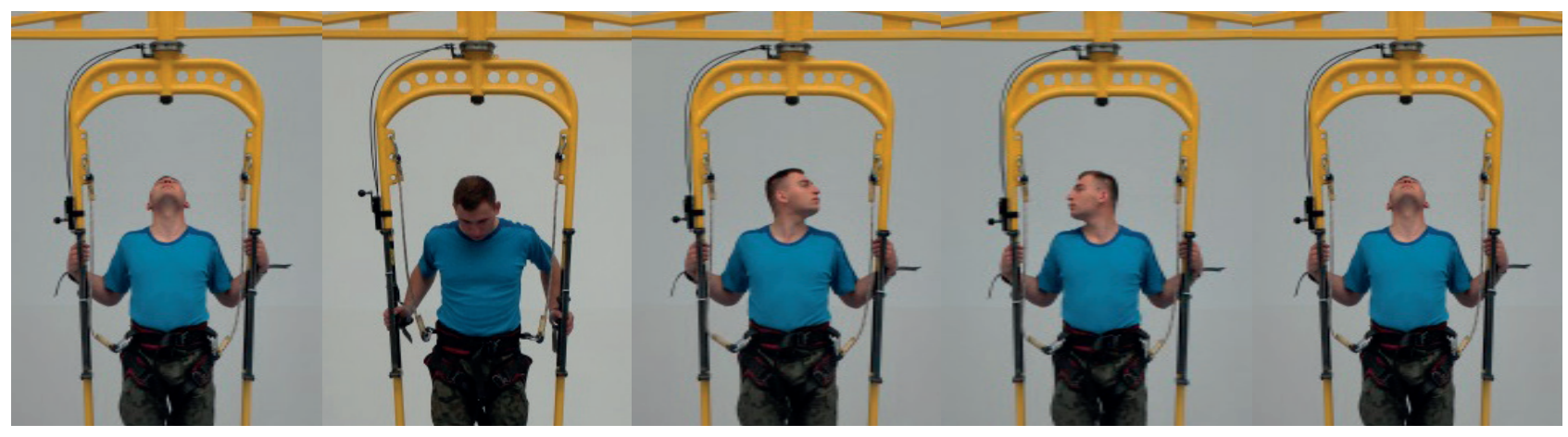

Figure 1. Test on the unlocked looping, taking into account the head movement direction

than group B, directly targeting the vestibular-vegetative system. It is also linked with the initial medical checkup, proved by the obtained health categories. In the adopted criteria for the classification of the vestibular-vegetative system's habituation level, during an attempt on the unlocked looping, cadets in group A achieved a good level as a result of using load in the training process. Cadets in group B achieved a sufficient level. Special attention needs to be given to the load connected with exercising in different axes on SAGI. An example of a body-load exercise is an exercise on the looping in the sagittal plane; after releasing the looping, there is an additional rotational movement along the axis of the body.
The research conducted on pilot cadets during identical exercises on SAGI, in biochemical parameters, showed a body load which was similar to athletes - triathlonists [5]. The specific characteristics of the conducted exercises on SAGI require adequate performance from cadets before starting the process of training on these instruments. In the process of training, the physical effort in groups $\mathrm{A}$ and B was in the range of aerobic metabolism. A higher intensity of physical effort was observed in group B than in group A. This is confirmed by a statistically higher average HR value in group B in contrast to group A, measured at the beginning and at the end of the training process. During the training unit, short-lasting accelerated HR values, 

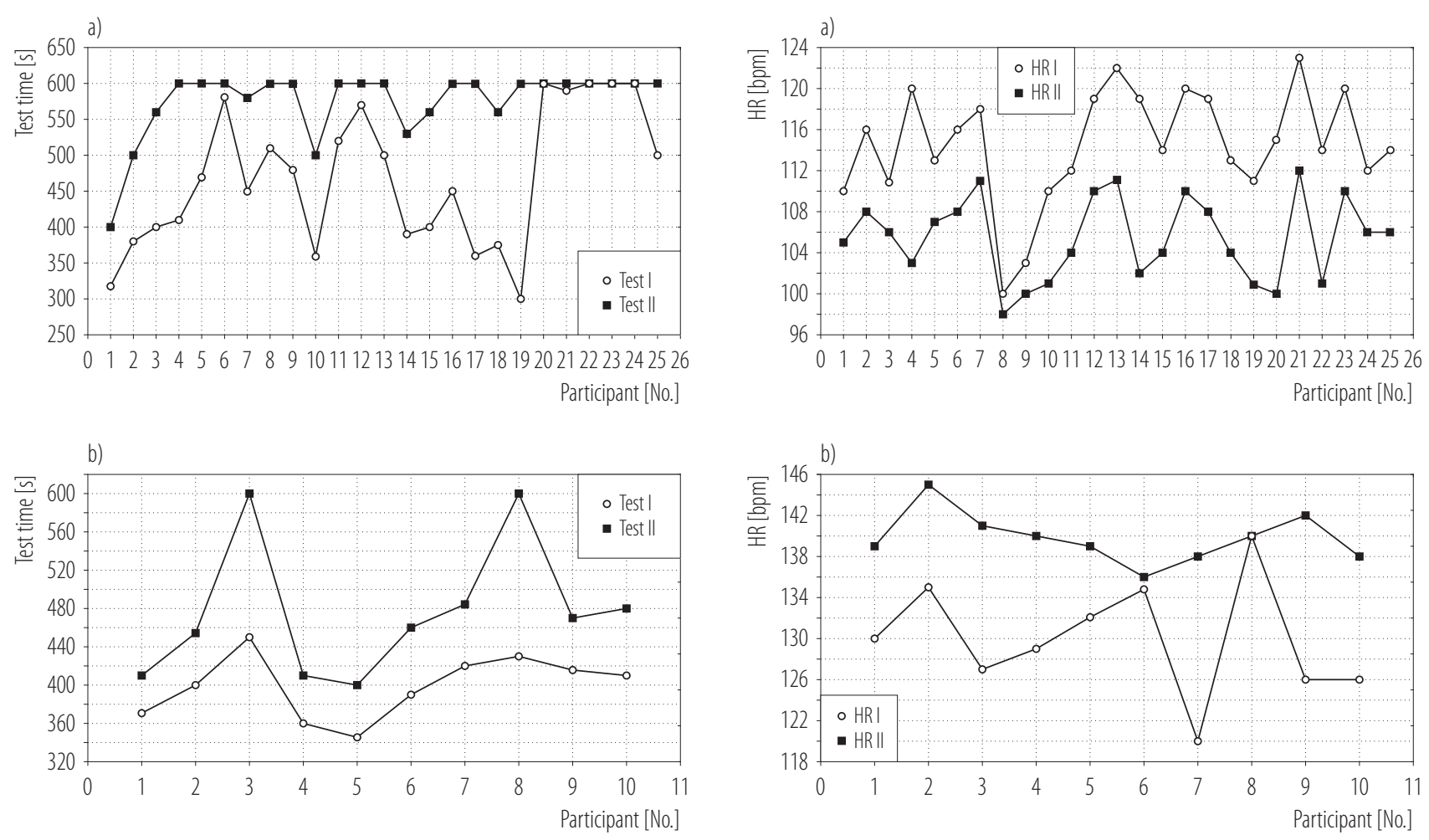

Figure 2. Results on the unlocked looping in a) group $\mathrm{A}$ $(\mathrm{N}=25$, tested $)$ and $\mathrm{b})$ group $\mathrm{B}(\mathrm{N}=10$, control $)$ of first-year students of the PAFA in Dęblin before and after the preparatory period

at $190 \mathrm{bpm}$, were also observed. Such changes were also shown in the research conducted by Kłossowski [12].

High HR values prove that the body, during exercises on SAGI, draws energy from anaerobic sources. Such a situation could have occurred during the looping practice (rotations), when the cadets were exposed to a positive acceleration (head-feet direction) and negative acceleration (feet-head direction). During this type of an exercise, a short-term oxygen deficit was likely to have occurred as a result of blood shift. In group B, HR values in the training process were rising, contrary to group A. This may have been caused by different program contents, aimed at comprehensive body development, with a focus on all motor skills. In the course of the training, the cadets did not manage to adapt their organisms to the exercise program used.

Figure 3. Heart rate values in a) group $A(N=25$, tested $)$ and b) group $B(N=10$, control) of first-year students of the PAFA in Dęblin - before and after the preparatory period

In the process of training on SAGI, a gradual decrease in HR was noticeable, which could have been caused by adaptation to this type of effort, or may have been related to mastering the technique of exercising on SAGI. It may also be connected with the final part of the activities, during which the trainees are lying down on mattresses and doing breathing exercises. The lying position may stimulate the parasympathetic nervous system. This is consistent with studies published by other authors, who found that, among 3 other positions, the lying position accelerates and reactivates the parasympathetic system [15].

The dynamic exercises on SAGI, in different body axes, affect the 3 semicircular canals of the vestibular organs and the otolith organ. It was found that in the semicircular ducts (ductus semicirculares) and in the vestibule (vestibulum), there are receptors of equilibrium. The recep- 
tor cells in the membranous ampullae of the semicircular canals (ampullae membranacea ductus semicirculares) respond to the head rotation, i.e., angular accelerations, whereas the sensory cells which are present in the utricle and the pouch are sensitive to linear accelerations $[11,16]$. In the off-vertical axis rotation (OVAR), which has sinusoidal characteristics, eye movement reactions appear to be the result of a combination of the semicircular canals and otoliths $[17,18]$. It was demonstrated that the head movement in different directions (rotation, twist, bend) increases susceptibility to space motion sickness $[19,20]$. The majority of space motion sickness cases are related to the vestibule [21-23], although the organ of sight plays a crucial role [24-27].

Dai et al. [28] developed an interesting concept model of generating motion sickness during rotations around the longitudinal body axis. When stimulating the vestibular organs under normal gravity by applying a rotational movement, it was possible to obtain transient phase vestibular potentials from the central nervous system. In contrast, an inclusion of a swinging motion triggered a long-term vestibular potential, possibly caused by stimulating otoliths. In conditions of zero gravity, only phase vestibular evoked potentials were recorded, which were produced as a result of stimulating the receptors of vertical semicircular canals, by the swinging movements, without otolith organs [29]. Thus, it is evident that exercises on SAGI, performed in the longitudinal axis and in the sagittal axis, trigger kinetic stimuli in cadets in an appropriate rhythm, effecting the semicircular canals and otolith organs (gravity $1 \mathrm{G}$ ). In the symptoms of habituation, there is a decreased response of receptors to recurring kinetic stimuli. This type of accelerations occurs while performing different types of flights, e.g., during a turn, barrel roll, loop, dive or spin. In such conditions, military pilots frequently experience spatial disorientation. Studies have shown that the phenomenon of illusion in the tilting plane in a controlled aircraft is likely to occur even after a short rotational manoeuver. Therefore, disorientation scenarios should become part of a training program to avoid spatial disorientation in pilots [30].

Taking into account the role of rotational exercises in shaping spatial orientation and lowering sensitivity to space motion sickness, a research experiment was conducted on SAGI. In order to assess the effects of training, particularly those pertaining to vestibular habituation, the unlocked looping test (Jędrys test) was made. The test has been re-used and verified practically at the PAFA for several years [4]. The unlocked looping test, unlike the Coriolis effect, is different due to the fact that it was executed for a longer period of time, in a standing position, and that it is specially designed to evaluate the effects of the training process with regard to vestibular habituation and spatial orientation. The attempt is of a tremendous diagnostic value in terms of the autonomic nervous system of a pilot preparing for highly maneuverable flights. Obtaining a statistically significant time difference in the performance of this test between examinations I and II indicates an efficient application of the training program on SAGI as well as achieving vestibular habituation. It is worth noting that vestibular habituation occurs more quickly and is memorized longer, even under weaker stimuli. It is considered that in the process of habituation, apart from peripheral chemoreceptors, also brain subcortical structures are used, including reticular formation [11].

The unlocked looping is always accompanied by physical effort, which is absent in the rotational Coriolis test. The standing position, while performing this test, also gives information about an orthostatic capability, which undoubtedly plays a significant role in the pilot's and astronaut's organism. It was demonstrated that the parasympathetic component is particularly expressed at the age of 20, dominating the activation of the sympathetic nervous system during rest and in a standing position. The effect of parasympathetic inhibition diminishes with age [31]. At this point, it should be stressed that in 
the aging process of the autonomic system, changes occur in the sensitivity of baroreflexes and in the central modulation of sympathetic stimulation. In the case of a pressure cardiac stress response of the circulatory system deriving from the peripheral innervation, it does not undergo significant changes with time [32]. Due to tilting, the venous blood returns to the heart.

The stimulation of the sympathetic system, in response to the irritation of the baroreceptor reflexes, leads to increased vascular resistance and arterial pressure. In healthy persons, the baroreceptor reflexes positively affect cerebral perfusion. The occurring postural hypotension is a symptom of an impaired function of the sympathetic system. Postural hypotension causes cerebral hypoperfusion with such symptoms as the loss of consciousness, dizziness, blurred vision, and balance disorders associated with tilting [33]. After flights in space, it was possible to observe reduced orthostatic tolerance in the tilt test, manifesting itself in a decline in the blood volume, increased blood retention in the lower limbs and a decrease in heart output [34]. It seems that, contrary to some opinions [12], SAGI practice has a beneficial effect on the tolerance of $+\mathrm{Gz}$ accelerations. Performing rotations on SAGI is a typical effect (workout) on the circulatory-respiratory system as well as low- and high-pressure baroreceptor reflexes caused by $+\mathrm{Gz}$ (head-feet direction) and $-\mathrm{Gz}$ (feet-head direction) accelerations.

The exercises on SAGI were of tremendous importance in the early stages of flight training for cadet pilots, preventing adverse factors causing space motion sickness and spatial disorientation. They had a beneficial impact on improving the habituation of the vestibular organ.

\section{CONCLUSIONS}

It should be stressed that the cadets conducted workouts on SAGI in the range of aerobic metabolism, as confirmed by HR measurements, using the Polar Team2 Pro system. The exercises on SAGI have a beneficial impact on improving the habituation of the vestibular organ in train- ing cadets, expressed by a statistically significant extension of time of performing the rotational test on the unlocked looping, as opposed to output values and the control group. Thus, a significant improvement in the tolerance of angular accelerations and an increase in tolerance to space motion sickness were achieved. The research is the basis for using this method (Jędrys test) to practice special preparation for flights made by cadet pilots as an independent variable conditioning flight safety.

\section{REFERENCES}

1. Rawat N, Connor CW, Jones JA, Kozlowskaya IB, Sullivan P. The correlation between aerobic fitness and motion sickness susceptibility. Aviat Space Environ Med. 2002;3:216-8.

2. Stroud KJ, Harm DL, Klaus DM. Preflight Virtual Reality Training as a Countermeasure for Space Motion Sickness and Disorientation. Aviat Space Environ Med. 2005;76:352-6.

3. Viirre E, Clark JB. Airsickness and Space Sickness. In: Kennedy CH, Kayt GG. Aeromedical Psychology. Farnham, Burlington: Ashgate; 2013. p. 195-213, https://doi.org/10. 1201/9781315565811-8.

4. Jędrys R. [The influence of exercises performed on Special Aviation Gymnastic Instruments (SAGI) upon the habituation of the equilibrium organ]. Post Astronaut. 1992;12(24):63-8. Polish.

5. Wochynski Z, Sobiech K. Effect of exercise on Special Aviation Gymnastics Instruments on blood serum levels of selected biochemical indices. Ann Agricul Environ Med. 2014;1:106-11.

6. Wochyński Z, Sobiech K. Post-exercise proteinuria in cadets trained on Special Aerial Gymnastics Instruments. Int J Occup Med Environ Health. 2015;28(5):863-73, https://doi.org/ 10.13075/ijomeh.1896.00454.

7. Wochyński Z, Sobiech KA. Impact of Special Aviation Gymnastics Instruments training on selected hormones in cadets' blood serum and plasma. Int J Occup Med Environ Health. 2017;30(4):655-64, https://doi.org/10.13075/ijomeh. 1896.00904. 
8. The Research and Technology Organization of NATO. Human Consequences of Agile Aircraft. RTO-EN-12. AC/323 (HFM) TP/32 (2000).

9. Jia H, Cui G, Xie S, Tian D, Bi H, Guo S. Vestibular function in military pilots before and after $10 \mathrm{~s}$ at $+9 \mathrm{Gz}$ on a centrifuge. Aviat Space Environ Med. 2009;1:20-2, https://doi.org/ 10.3357/ASEM.2186.2009.

10. Richard O, Reinhart MD. Orientation. In: Basic flight physiology. 3rd ed. New York, Chicago: McGraw Hill; 2008. p. 125-52.

11. Traczyk WZ, Trzebski A. [Man's physiology]. Warszawa: Wydawnictwo Lekarskie PZWL; 2007. p. 165. Polish.

12. Kłossowski M. [Assessment of physiological reactions as a result of SAGI practice]. Post Med Lot. 1994;2. Polish.

13. Studenski R. [Psychological theory of accident causality and accident prevention]. Nowiny Psychol. 1988;4:57. Polish.

14. Wochyński Z, Jędrys R, Stelęgowski A. Methodology of training on special aviation gymnastic instruments. Dęblin: Air Force Academy; 2010. p. 43-59.

15. Buchheit M, Haddad HA, Laursen PB, Ahmaidi S. Effect of body posture on postexercise parasympathetic reactivation in men. Exp Physiol 2009;94:795-804, https://doi. org/10.1113/expphysiol.2009.048041.

16. Gresty MA, Bronstein AM. Testing otolith function. Br J Audiol. 1992;2:125-36, https://doi.org/10.3109/03005369209 077880 .

17. Furman JM, Schor RH, Schumann T. Off-vertical axis rotation: a test of the otolith-ocular reflex. Ann Otol Rhinol Laryngol. 1992;101:643-50, https://doi.org/10.1177/0003489 49210100803.

18. Tribukait A, Bergsten E, Eiken O. Variability in perceived tilt during a roll plane canal-otolith conflict in a gondola centrifuge. Aviat Space Environ Med. 2013;11b:1131-9, https:// doi.org/10.3357/ASEM.3655.2013.

19. Kubiczkowa J, Czech S. [Selected methods of examining the vestibular organ in the aspect of space motion sickness]. Med Lot. 1992;1-2:1-6. Polish.

20. Lackner JR, Graybiel A. Head movements elicitmotion sickness during exposure to microgravity and macrogravity acceleration levels. In: Igarshi M, Black FO, editors. Vestibular and Visual Controlon posture and Locomotor Equilibrium. New York, NY: Karger; 1985. p. 170-7, https://doi. org/10.1159/000410323.

21. Rabbit RD. Directional coding of three-dimensional movements by the vestibular semicircular canals. Biol Cybern. 1999;80:417-31, https://doi.org/10.1007/s004220050536.

22. Rine RM, Schubert MC, Balkany TJ. Visual-vestibular habituation and balance training for motion sickness. Phys Ther 1999;10:949-57, https://doi.org/10.1093/ptj/79.10.949.

23. Thornton WE, Moore TP, Pool SL, Vandrploeg J. Clinical characterization and etiology of space motion sickness. Aviat Space Environ Med. 1987;58(Suppl 9):A1-8.

24. Hu S, Stern RM, Koch KL. Effect preexposures a rotating optokinetic drum on adaptation to motion sickness. Aviat Space Environ Med. 1991;62:53-6.

25. Imai T, Takeda N, Uno A, Morita M, Koizuka I, Kubo T. Three-dimensional eye rotation axis analysis of benign paroxysmal positioning nystagmus. Acta Otolaryngol. 2002;64:417-23, https://doi.org/10.1159/000067567.

26. Watt DGD. The vestibulo-ocular reflex and its possible roles in space motion sickness. Aviat Space Environ Med. 1987;58(Suppl 9):A170-4.

27. Yang T, Pei J. Motion sickness severity under interaction of vection and head movements. Aviat Space Environ Med. 1991;62:141-4.

28. Dai M, Sofroniou S, Kunin M, Raphan T, Cohen B. Motion sickness induced by off-vertical axis rotation (OVAR). Exp Brain Res. 2010;204:207-22, https://doi.org/10.1007/s00221010-2305-4.

29. Probst T, Bablok E, Dabrowski H, Dabrowski J-H, Loose R, Wist ER. Position and velocity responses from the otoliths and the Casals: results from ESA's paraboli flights. Aviat Space Environ Med. 1996;67:633-9.

30. Nooij SAE, Groen EL. Rolling into spatial disorientation: Simulator demonstration of the post-roll (Gillingham) illusion. Aviat Space Environ Med. 2011;5:505-12, https://doi. org/10.3357/ASEM.2946.2011. 
31. Yamanaka Y, Honma K. Cardiovascular autonomic nervous response to postural change in 610 healthy Japanase subjects in relation to age. Aut Neuroscien Bas Clin. 2006;124:125-31.

32. Barantke M, Ortak J, Lieb W, Wilke I, Shunkert H, Bonnemeier $\mathrm{H}$. Effects of aging on reflex autonomic nervous response induced by orthostatic manoeuvers, PACE. 2007;3:198-202, https://doi.org/10.1111/j.1540-8159.2007.00637.x.

33. Tachtsidis I, Elwell C, Leong T, Bleasdale-Barr K, Hunt K, Toms N. Rate of change in cerebral oxygenation and blond pressure in response to passive changes in posture. In: Okunieff P, Williams J, Chen Y, editors. Oxygen Transport to Tissue XXVI. Adv Exp Med Biol. 2005;566:187-93, https:// doi.org/10.1007/0-387-26206-7_26.

34. Buckey JC Jr, Lane LD, Levine BD, Watenpaugh DE, Wright SJ, Moore WE, et al. Orthostatic intolerance after spaceflight. J Appl Physiol. 1996;81:7-18,https://doi.org/10. 1152/jappl.1996.81.1.7.

This work is available in Open Access model and licensed under a Creative Commons Attribution-NonCommercial 3.0 Poland License - http://creativecommons.org/ licenses/by-nc/3.0/pl/deed.en. 